\title{
Convergence of some iterations for generalized Kannan type mappings in $b$-metric spaces
}

\author{
Nilakshi Goswami ${ }^{1}$, Nehjamang Haokip $^{2 *}$ and Deepmala Rai ${ }^{3}$ \\ ${ }^{1}$ Department of Mathematics, Gauhati University, Guwahati, Assam, India \\ ${ }^{2}$ Department of Mathematics, Churachandpur College, Churachandpur, Manipur, India \\ ${ }^{3}$ Mathematics Discipline, PDPM Indian Institute of Information Technology, Design and Manufacturing, Jabalpur, India
}

Received: 24 May 2019, Accepted: 24 June 2019

Published online: 26 December 2019.

\begin{abstract}
In this paper, we derive some fixed point theorems for generalized Kannan type mappings in $b$-metric spaces. We also introduce a Picard-Ishikawa iteration scheme in a convex $b$-metric space and prove a strong convergence result for the same. Moreover, we define a generalized Jungck-Kannan type mapping $T$ with respect to $S$ and prove the existence of a unique common fixed point with a convergence result. The results are supported by suitable examples.
\end{abstract}

Keywords: $b$-metric space, Picard-Ishikawa iteration, Kannan type mappings.

\section{Introduction}

In 1922, Banach proved the famous "Banach Contraction Principle" for metric spaces which initiated the study of fixed point theory in different directions. Several research workers have been engaged for developing interesting results in this field by taking different types of mappings as well as different generalized spaces (for instance, refer to [7] - [11], [16], [17], [18], [20] - [23], [26], [27], [32] and the references therein).

With the existence of the unique fixed point, Banach also showed the convergence of the sequence of Picard's iterates to the fixed point. Since then a number of authors proved the convergence of different iteration schemes to the unique fixed point. Some of the prominent authors in this regard are Mann [19] in 1953, Ishikawa [15] in 1974, Jungck [16] in 1976, Agarwal et al. [2] in 2007, etc. Many authors have also proved the convergence of combination of the known iteration schemes (for example, [25], [30], etc.).

To generalize Banach fixed point theorem, in 1989, Bakhtin [3] introduced $b$-metric spaces. But in 1993, Czerwik [6] formally defined the notion of b-metric spaces as follows.

Definition 1. [6] Let $X$ be a non empty set and $s \geq 1$ be a given real number. A function $d: X \times X \longrightarrow[0, \infty)$ is called $b$-metric if it satisfies the following properties.

(1) $d(x, y)=0$ if and only if $x=y$;

(2) $d(x, y)=d(y, x) ; \quad$ and

(3) $d(x, z) \leq s[d(x, y)+d(y, z)], \quad$ for all $x, y, z \in X$.

The pair $(X, d)$ is called a b-metric space with coefficient s.

\footnotetext{
* Corresponding author e-mail: mark02mm@yahoo.co.in
} 
There are several examples of $b$-metric in various existing literatures (refer to [5], [29] and the references therein). A $b$-metric need not be always continuous. An example is given in [24].

In 1970, the concept of convex structure in a metric space was introduced by Takahashi [31] as follows (one may also refer to [1]).

Definition 2. [31] Let $(X, d)$ be a metric space. A mapping $\mathscr{W}: X^{2} \times[0,1] \longrightarrow X$ satisfying

$$
d(z, \mathscr{W}(x, y, t)) \leq t d(z, x)+(1-t) d(z, y)
$$

for all $x, y, z \in X$ and $t \in[0,1]$ is called a convex structure on $X . A$-metric space $(X, d)$ on which a convex structure $\mathscr{W}$ is defined is called a convex $b$-metric space, denoted by $(X, \mathscr{W}, d)$. A subset $K$ of $X$ is called convex if $\mathscr{W}(x, y, \lambda) \in K$ whenever $x, y \in K$ and $\lambda \in[0,1]$.

The above notions of convex structure and convex metric space extends naturally to $b$-metric spaces by the condition

$$
s d(z, \mathscr{W}(x, y, t)) \leq t d(z, x)+(1-t) d(z, y)
$$

In [13], we have obtained the following fixed point result for a generalized Kannan type mapping and a continuous $b$-metric $d$.

Theorem 1. [13] Let $(X, d)$ be a complete b-metric space with coefficient $s \geq 1$ and let $f: X \longrightarrow X$ be a mapping such that there exists $p<\frac{1}{2 s+1}$ satisfying

$$
\phi(d(f x, f y)) \leq p(\phi(d(x, y))+\phi(d(x, f x))+\phi(d(y, f y)))
$$

for all $x, y \in X$. Then $f$ has an unique fixed point $z \in X$, and for any $x \in X$ the sequence of iterates $\left\{f^{n} x\right\}$ converges to $z$ and for $q=\frac{2 p}{1-p}<1$,

$$
d\left(f^{n+1} x, f^{n} x\right) \leq q^{n} d(x, f x), n=0,1,2, \ldots
$$

In this result, $\phi$ is a subadditive altering distance function.

Definition 3. [13] A function $\phi:[0, \infty) \longrightarrow[0, \infty)$ is said to be a subadditive altering distance function if

(i) $\phi$ is an altering distance function [11], (i.e., $\phi$ is continuous, strictly increasing and $\phi(t)=0$ if and only if $t=0$ )

(ii) $\phi(x+y) \leq \phi(x)+\phi(y) \quad \forall x, y \in[0, \infty)$

For example, the functions $\phi_{1}(x)=k x$ for some $k \geq 1, \phi_{2}(x)=\sqrt[n]{x}, n \in \mathbb{N}, \phi_{3}(x)=\log (1+x), x \geq 0$ and $\phi_{4}(x)=\tan ^{-1} x$ are such subadditive altering distance functions as mentioned in [13].

Here we note, if $\phi$ is sub-additive, then for $k<1$

$$
\phi(d(x, y)) \leq k \phi(d(a, b)) \quad \Longrightarrow \quad d(x, y) \leq k d(a, b) \quad \text { (refer to [13]) }
$$

For a self map $f$ on a convex $b$-metric space $(X, \mathscr{W}, d)$ and for $x_{0} \in X$, we now define Picard-Ishikawa type iteration scheme as:

$$
\left.\begin{array}{ll}
x_{n+1} & =f y_{n} \\
y_{n} & =\mathscr{W}\left(x_{n}, f z_{n}, \alpha_{n}\right), \\
z_{n} & =\mathscr{W}\left(x_{n}, f x_{n}, \beta_{n}\right)
\end{array}\right\}
$$


where $\left\{\alpha_{n}\right\}$ and $\left\{\beta_{n}\right\}$ are real sequences in $(0,1)$.

The above iteration scheme may be put in the following form

$$
x_{n+1}=\mu\left(f, x_{n}\right),
$$

where $\mu\left(f, x_{n}\right)=f\left(\mathscr{W}\left(x_{n}, f\left(\mathscr{W}\left(x_{n}, f x_{n}, \beta_{n}\right)\right), \alpha_{n}\right)\right)$.

\section{Main results}

Consider a subadditive altering distance function $\phi$ and let the $b$-metric $d$ be continuous in the topology generated by it.

Theorem 2. Let $f: X \longrightarrow X$ be a self map on a complete b-metric space $(X, d)$ with coefficient $s \geq 1$ such that there exists $p<\frac{1}{2 s+1}$ satisfying

$$
\phi(s d(f x, f y)) \leq p(\phi(d(x, y))+\phi(d(x, f x))+\phi(d(y, f y)))
$$

for all $x, y \in X$. Then $f$ has a unique common fixed point $z \in X$. Moreover, for any $x_{0} \in X$ the sequence $\left\{x_{n}\right\}$ generated by the iteration (2), $x_{n+1}=\mu\left(f, x_{n}\right), n \geq 0$ converges strongly to the unique common fixed point.

Proof. The existence of a unique fixed point and the strong convergence of the Picard's iteration to the fixed point has been shown in [13]. We shall now show that the sequence $\left\{x_{n}\right\}$ of iterates given by (2) strongly converges to the unique fixed point of $f$. To see this, let $w$ be the fixed point of $f$ and note that

$$
\begin{aligned}
\phi\left(s d\left(x_{n+1}, w\right)\right) & =\phi\left(s d\left(f y_{n}, w\right)\right) \leq p\left(\phi\left(d\left(y_{n}, w\right)\right)+\phi\left(d\left(y_{n}, f y_{n}\right)\right)+\phi(0)\right) \\
& =p \phi\left(d\left(y_{n}, w\right)\right)+s p \phi\left(d\left(y_{n}, w\right)\right)+s p \phi\left(d\left(f y_{n}, w\right)\right) .
\end{aligned}
$$

Since $x_{n+1}=f y_{n}$, we get

$$
\phi\left(s d\left(x_{n+1}, w\right)\right) \leq \frac{p(1+s)}{1-s p} \phi\left(d\left(y_{n}, w\right)\right),
$$

or,

$$
d\left(x_{n+1}, w\right) \leq k d\left(y_{n}, w\right),
$$

where $k=\frac{p(1+s)}{1-s p}<1$. Now, $d\left(y_{n}, w\right)=d\left(\mathscr{W}\left(x_{n}, f z_{n}, \alpha_{n}\right), w\right) \leq\left(1-\alpha_{n}\right) d\left(x_{n}, w\right)+\alpha_{n} d\left(f z_{n}, w\right)$.

By the same argument as in the above, we get

$$
d\left(f z_{n}, w\right) \leq k d\left(z_{n}, w\right) .
$$

Again, $d\left(z_{n}, w\right)=d\left(\mathscr{W}\left(x_{n}, f x_{n}, \beta_{n}\right), w\right) \leq\left(1-\beta_{n}\right) d\left(x_{n}, w\right)+\beta_{n} d\left(f x_{n}, w\right)$. Similarly, we get

$$
d\left(f x_{n}, w\right) \leq k d\left(x_{n}, w\right) .
$$

Summing up, we get

$$
\begin{aligned}
d\left(x_{n+1}, w\right) & \leq k d\left(y_{n}, w\right) \leq k\left(\left(1-\alpha_{n}\right) d\left(x_{n}, w\right)+\alpha_{n} d\left(f z_{n}, w\right)\right) \leq k\left(1-\alpha_{n}\right) d\left(x_{n}, w\right)+k^{2} \alpha_{n} d\left(z_{n}, w\right) \\
& \leq k\left(1-\alpha_{n}\right) d\left(x_{n}, w\right)+k^{2} \alpha_{n}\left(\left(1-\beta_{n}\right) d\left(x_{n}, w\right)+k \beta_{n} d\left(x_{n}, w\right)\right) \leq k d\left(x_{n}, w\right) .
\end{aligned}
$$


Continuing inductively, we get

$$
d\left(x_{n+1}, w\right) \leq k^{n} d\left(x_{0}, w\right)
$$

and hence

$$
\lim _{n \rightarrow \infty} d\left(x_{n}, w\right)=0
$$

This completes the proof.

Remark. For $x_{0} \in X$, the Mann iteration is given by

$$
x_{n+1}=\mathscr{W}\left(x_{n}, f x_{n}, \alpha_{n}\right)
$$

where $\left\{\alpha_{n}\right\}$ is a sequence in $[0,1]$. Now,

$$
d\left(x_{n+1}, w\right)=d\left(\mathscr{W}\left(x_{n}, f x_{n}, \alpha_{n}\right), w\right) \leq\left(1-\alpha_{n}\right) d\left(x_{n}, w\right)+\alpha_{n} d\left(f x_{n}, w\right) .
$$

But

$$
\begin{aligned}
\phi\left(d\left(f x_{n}, w\right)\right) & \leq p\left(\phi\left(d\left(x_{n}, w\right)\right)+\phi\left(d\left(x_{n}, f x_{n}\right)\right)+\phi(d(w, f w))\right) \\
& \leqq p \phi\left(d\left(x_{n}, w\right)\right)+\operatorname{sp} \phi\left(d\left(x_{n}, w\right)\right)+\operatorname{sp} \phi\left(d\left(f x_{n}, w\right)\right),
\end{aligned}
$$

that is,

$$
\phi\left(d\left(f x_{n}, w\right)\right) \leq k \phi\left(d\left(x_{n}, w\right)\right)
$$

where $k=\frac{p(1+s)}{1-s p}<1$, and hence

$$
d\left(f x_{n}, w\right) \leq k d\left(x_{n}, w\right)
$$

Thus,

$$
d\left(x_{n+1}, w\right) \leq\left(1-\alpha_{n}\right) d\left(x_{n}, w\right)+k \alpha_{n} d\left(x_{n}, w\right) \leq k^{\prime} d\left(x_{n}, w\right),
$$

for some $k^{\prime}<1$. The strong convergence of the Mann iteration then follows as in the above proof.

Remark. For $x_{0} \in X$, the Ishikawa iteration is given by

$$
\begin{aligned}
x_{n+1} & =\mathscr{W}\left(x_{n}, f y_{n}, \alpha_{n}\right) \\
y_{n} & =\mathscr{W}\left(x_{n}, f x_{n}, \beta_{n}\right)
\end{aligned}
$$

where $\left\{\alpha_{n}\right\}$ and $\left\{\beta_{n}\right\}$ are sequences in $[0,1]$. As in the previous remark, we get

$$
\phi\left(d\left(f y_{n}, w\right)\right) \leq k \phi\left(d\left(y_{n}, w\right)\right)
$$

and hence

$$
d\left(f y_{n}, w\right) \leq k d\left(y_{n}, w\right) .
$$

Similarly,

$$
d\left(f x_{n}, w\right) \leq k d\left(x_{n}, w\right) .
$$


Hence

$$
\begin{aligned}
d\left(x_{n+1}, w\right) & \leq\left(1-\alpha_{n}\right) d\left(x_{n}, w\right)+\alpha_{n} d\left(f y_{n}, w\right) \leq\left(1-\alpha_{n}\right) d\left(x_{n}, w\right)+k \alpha_{n} d\left(y_{n}, w\right) \\
& \leq\left(1-\alpha_{n}\right) d\left(x_{n}, w\right)+k \alpha_{n}\left(\left(1-\beta_{n}\right) d\left(x_{n}, w\right)+\beta_{n} d\left(f x_{n}, w\right)\right) \\
& \leq\left(1-\alpha_{n}+k \alpha_{n}\left(1-\beta_{n}\right)+k^{2} \alpha_{n} \beta_{n}\right) d\left(x_{n}, w\right) \\
& \leq k^{\prime} d\left(x_{n}, w\right)
\end{aligned}
$$

for some $k^{\prime}<1$. The strong convergence of the sequence $\left\{x_{n}\right\}$ follows as in the previous results.

We note here that the Jungck-Mann, Jungck-Ishikawa and the modified Jungck-Ishikawa iterations also converges strongly to the unique fixed point of $f$ satisfying (3).

In the following, we extend the result of Theorem 2 for a generalized Jungck-Kannan type contraction mappings and prove an existence result for a common fixed point.

Theorem 3. Let $f, g: X \longrightarrow X$ be commuting self maps on a complete $b$-metric space $(X, d)$ with coefficient $s \geq 1$ such that there exists $p<\frac{1}{2 s+1}$ satisfying

$$
\phi(s d(f x, f y)) \leq p(\phi(d(g x, g y))+\phi(d(g x, f x))+\phi(d(g y, f y)))
$$

for all $x, y \in X$ with $f(X) \subseteq g(X)$. Then $f$ and $g$ have a unique common fixed point $w \in X$. Moreover, for any $x_{0} \in X$ the sequence $\left\{g x_{n}\right\}$ generated by the Jungck-Picard iteration, $g x_{n+1}=f x_{n}, n \geq 0$ converges strongly to the unique common fixed point.

Proof.For an arbitrary element $x \in X$, let $f x=g u$ for some $u \in X$. Then

$$
\phi(s d(g u, f u))=\phi(s d(f x, f u)) \leq p(\phi(d(g x, g u))+\phi(d(g x, f x))+\phi(d(g u, f u)))
$$

that is,

$$
\phi(s d(g u, f u)) \leq q \phi(d(g x, f x)) \quad \text { where } \quad q=\frac{2 p}{1-p}<1
$$

Thus

$$
d(g u, f u) \leq q d(g x, f x)
$$

Now, for an arbitrary point $x_{0} \in X$ consider the sequence $\left\{g x_{n}\right\}$ where $g x_{n+1}=f x_{n}, n=0,1,2, \ldots$ Then $\left\{g x_{n}\right\}$ is a Cauchy sequence in $X$, and so, there exists $w \in X$ such that

$$
\lim _{n \rightarrow \infty} g x_{n+1}=\lim _{n \rightarrow \infty} f x_{n}=w
$$

Now,

$$
\phi(s d(f w, g w)) \leq \phi\left(s d\left(f w, f x_{n}\right)+s^{2} d\left(f x_{n}, g x_{n}\right)+s^{2} d\left(g x_{n}, g w\right)\right)
$$

from which, using (3) we get

$$
\begin{aligned}
(1-s p) \phi(s d(f w, g w)) & \leq\left(s p+s^{2}\right)\left(\phi\left(d\left(g w, g x_{n}\right)\right)+\phi\left(d\left(f x_{n}, g x_{n}\right)\right)\right) \\
& \leq\left(s p+s^{2}\right)\left(\phi\left(d\left(g w, g x_{n}\right)\right)+\phi\left(q^{n} d\left(g x_{0}, f x_{0}\right)\right)\right)
\end{aligned}
$$


Since it is satisfied for all $n \in \mathbb{N}$ and $1-s p \neq 0$, so

$$
\phi(s d(f w, g w)) \longrightarrow 0, \quad \text { as } n \rightarrow \infty,
$$

showing that $d(f w, g w)=0$. To show the uniqueness of the coincidence point $w$, let $w^{\prime} \in X$ be another coincidence point of $f$ and $g$. Then from (3),

$$
\begin{aligned}
\phi\left(d\left(w, w^{\prime}\right)\right) & =\phi\left(d\left(f w, f w^{\prime}\right)\right) \leq \phi\left(s d\left(f w, f w^{\prime}\right)\right) \leq p\left\{\phi\left(d\left(g w, g w^{\prime}\right)\right)+\phi(d(g w, f w))+\phi\left(d\left(g w^{\prime}, f w^{\prime}\right)\right)\right\} \\
& \leq p \phi\left(d\left(w, w^{\prime}\right)\right) .
\end{aligned}
$$

As $\phi$ is strictly increasing and $p<\frac{1}{2 s+1}$, this holds if and only if $d\left(w, w^{\prime}\right)=0$.

Now, let $v=g w=f w$. Then

$$
g v=g f w=f g w=f v,
$$

showing that $v$ is a coincidence point of $f$ and $g$, and by the uniqueness of the coincidence point, we get that $v=w$, which shows that $w$ is a common fixed point of $f$ and $g$. The uniqueness follows from (3).

Finally,

$$
\begin{aligned}
\phi\left(d\left(g x_{n+1}, z\right)\right) & =\phi\left(d\left(f x_{n}, w\right)\right) \leq p\left(\phi\left(d\left(g x_{n}, w\right)\right)+\phi\left(d\left(g x_{n}, f x_{n}\right)\right)+\phi(0)\right) \\
& \leq p\left(\phi\left(d\left(g x_{n}, w\right)\right)+s \phi\left(d\left(g x_{n}, w\right)\right)+s \phi\left(d\left(w, g x_{n+1}\right)\right)\right)
\end{aligned}
$$

or,

$$
\phi\left(d\left(g x_{n+1}, w\right)\right) \leq \frac{p(s+1)}{1-s p} \phi\left(d\left(g x_{n}, w\right)\right)
$$

Continuing inductively, we get

$$
\phi\left(d\left(g x_{n+1}, w\right)\right) \leq k^{n} \phi\left(d\left(g x_{0}, w\right)\right)
$$

where $k=\frac{p(s+1)}{1-s p}<1$ and hence

$$
\lim _{n \rightarrow \infty} \phi\left(d\left(g x_{n}, w\right)\right)=0
$$

and consequently

$$
\lim _{n \rightarrow \infty} d\left(g x_{n}, w\right)=0
$$

This proves the result.

Example 1. Consider $X=[0,1]$ and $d(x, y)=|x-y|^{2}$ for all $x, y \in X$. Then $(X, d)$ is a complete $b$-metric space. Let $f, g: X \longrightarrow X$ be given by $g x=\frac{x}{2}, f x=\frac{x}{4}$ for all $x \in X$. We note here that $f(X) \subseteq g(X)$ and $f g x=g f x$ for all $x \in X$. For $\phi(t)=\log (1+t)$, condition (4) reduces to

$$
\begin{aligned}
&(1+d(f x, f y))^{k} \leq(1+d(g x, g y))(1+d(g x, f x))(1+d(g y, f y)) \\
& \Longrightarrow \quad\left(1+\frac{|x-y|^{2}}{16}\right)^{k} \leq\left(1+\frac{|x-y|^{2}}{4}\right)\left(1+\left|\frac{x}{2}-\frac{x}{4}\right|^{2}\right)\left(1+\left|\frac{y}{2}-\frac{y}{4}\right|^{2}\right) \\
& \Longrightarrow \quad\left(1+\frac{|x-y|^{2}}{16}\right)^{k} \leq\left(1+\frac{|x-y|^{2}}{4}\right)\left(1+\frac{x^{2}}{16}\right)\left(1+\frac{y^{2}}{16}\right)
\end{aligned}
$$

for some $k>3$. It can be easily checked that the relation holds true for all $x, y \in X$. Thus $f$ and $g$ are commuting maps satisfying (4) with $f(X) \subseteq g(X)$ and 0 is their common fixed point, which is unique.

We note here that if we take $d(x, y)=|x-y|$ instead, condition (4) is not satisfied for the same $f$ and $g$. 
Now we define Jungck-Ishikawa type iteration scheme with respect to $f$ and $g$. For the convex $b$-metric space $(X, d, \mathscr{W})$ and $x_{0} \in X$, we take

$$
\left.\begin{array}{rl}
g x_{n+1} & =f y_{n} \\
g y_{n} & =\mathscr{W}\left(g x_{n}, f z_{n}, \alpha_{n}\right), \\
g z_{n} & =\mathscr{W}\left(g x_{n}, f x_{n}, \beta_{n}\right)
\end{array}\right\}
$$

where $\left\{\alpha_{n}\right\}$ and $\left\{\beta_{n}\right\}$ are real sequences in $(0,1)$. The above iteration scheme may be put in the following form

$$
g x_{n+1}=\mu\left(g, f, x_{n}\right)
$$

where $\mu\left(g, f, x_{n}\right)=f\left(\mathscr{W}\left(g x_{n}, f\left(\mathscr{W}\left(g x_{n}, f x_{n}, \beta_{n}\right)\right), \alpha_{n}\right)\right)$.

Theorem 4. Let $f, g: X \longrightarrow X$ be commuting self maps on a complete convex $b$-metric space $(X, d, \mathscr{W})$ with coefficient $s \geq 1$ satisfying (3) for some $p<\frac{1}{2 s+1}$ with $f(X) \subseteq g(X)$. Then the sequence $\left\{g x_{n}\right\}$ of iterates given by (6) strongly converges to the unique common fixed point of $f$ and $g$.

Proof. The existence of the unique common fixed point is shown in Theorem 3 . To show that the sequence $\left\{g x_{n}\right\}$ given by the iteration scheme (6) strongly converges to the unique common fixed point, let $w \in X$ be the common fixed point of $f$ and $g$. Now,

$$
\phi\left(d\left(g x_{n+1}, w\right)\right)=\phi\left(d\left(f y_{n}, w\right)\right) \leq p \phi\left(d\left(g y_{n}, w\right)\right)+\operatorname{sp} \phi\left(d\left(g y_{n}, w\right)\right)+\operatorname{sp} \phi\left(d\left(f y_{n}, w\right)\right)
$$

Since $g x_{n+1}=f y_{n}$, we get

$$
\phi\left(d\left(g x_{n+1}, w\right)\right) \leq \frac{p(1+s)}{1-s p} \phi\left(d\left(g y_{n}, w\right)\right)
$$

or,

$$
d\left(g x_{n+1}, w\right) \leq k d\left(g y_{n}, w\right)
$$

where $k=\frac{p(1+s)}{1-s p}<1$. Now,

$$
d\left(g y_{n}, w\right)=d\left(\mathscr{W}\left(g x_{n}, f z_{n}, \alpha_{n}\right), w\right) \leq\left(1-\alpha_{n}\right) d\left(g x_{n}, w\right)+\alpha_{n} d\left(f z_{n}, w\right) .
$$

By the same argument as in the above, we get

$$
d\left(f z_{n}, w\right) \leq k d\left(g z_{n}, w\right)
$$

Again,

$$
d\left(g z_{n}, w\right)=d\left(\mathscr{W}\left(g x_{n}, f x_{n}, \beta_{n}\right), w\right) \leq\left(1-\beta_{n}\right) d\left(g x_{n}, w\right)+\beta_{n} d\left(f x_{n}, w\right)
$$

Similarly, we get

$$
d\left(f x_{n}, w\right) \leq k d\left(g x_{n}, w\right)
$$

Summing up, we get

$$
\begin{aligned}
d\left(g x_{n+1}, w\right) & \leq k d\left(g y_{n}, w\right) \leq k\left(\left(1-\alpha_{n}\right) d\left(g x_{n}, w\right)+\alpha_{n} d\left(f z_{n}, w\right)\right) \leq k\left(1-\alpha_{n}\right) d\left(g x_{n}, w\right)+k^{2} \alpha_{n} d\left(g z_{n}, w\right) \\
& \leq k\left(1-\alpha_{n}\right) d\left(g x_{n}, w\right)+k^{2} \alpha_{n}\left(\left(1-\beta_{n}\right) d\left(g x_{n}, w\right)+k \beta_{n} d\left(g x_{n}, w\right)\right) \\
& \leq k d\left(g x_{n}, w\right)
\end{aligned}
$$

Proceeding as in the proof of Theorem 3, we get the desired result. 
Corollary 1. Let $f, g: X \longrightarrow X$ be commuting self maps on a complete $b$-metric space $(X, d)$ with coefficient $s \geq 1$ such that

$$
d(f x, f y) \leq p\{d(g x, g y)+d(g x, f x)+d(g y, f y)\} \quad \forall x, y \in X
$$

where $p<\frac{1}{2 s+1}$ with $f(X) \subseteq g(X)$. Then $f$ and $g$ has a unique common fixed point $z \in X$.

Proof. The result follows from Theorem 3 on taking $\phi(x)=x, x \in X$.

Corollary 2. Let $f, g: X \longrightarrow X$ be commuting self maps on a complete b-metric space $(X, d)$ with coefficient $s \geq 1$ such that for some positive integer $k$

$$
\phi\left(d\left(f^{k} x, f^{k} y\right)\right) \leq p\left\{\phi(d(g x, g y))+\phi\left(d\left(g x, f^{k} x\right)\right)+\phi\left(d\left(g y, f^{k} y\right)\right)\right\}
$$

for some $p<\frac{1}{2 s+1}$ and for all $x, y \in X$. Then there exists a unique common fixed point of $f$ and $g$.

Proof. We note that if $f$ and $g$ commutes, that is, $f g x=g f x$ for all $x \in X$, then $g f^{k} x=f^{k} g x$ for all $x \in X$, which shows $g$ and $f^{k}$ commutes for some $k \in \mathbb{N}$. Applying Theorem 2 to the self mapping $T=f^{k}$, we get that $g$ and $T$ has a unique common fixed point, say $w$, so that $f^{k} w=g w=w$.

Since $f^{k+1} w=f w$

$$
g f w=f^{k}(f w)=f^{k+1} w=f w
$$

and so $f w$ is a common fixed point of $g$ and $T$. By the uniqueness of the common fixed point of $g$ and $T$, we get $f w=w$ and hence $w$ is a common fixed point of $f$ and $g$. The uniqueness follows from the fact that if $w$ is a fixed point of $f$, so is it for $T$.

\section{Stability}

Harder \& Hicks [14] have defined and proved a $T$-stability result for iteration converging to the fixed point in a metric space. The same notion can be extended naturally to $b$-metric spaces.

Definition 4. [14] Let $f: X \longrightarrow X$ and $w$ be a fixed point of $f$, that is, $f w=w$. For any $x_{0} \in X$, let the sequence $\left\{x_{n}\right\}$ generated by the iterative scheme (2) converges to $w$. Let $\left\{x_{n}^{\prime}\right\}$ be an arbitrary sequence, and set $\varepsilon_{n}=d\left(x_{n+1}^{\prime}, \mu\left(f, x_{n}^{\prime}\right)\right)$, $n=0,1,2, \ldots$ Then the iterative scheme $\mu\left(f, x_{n}\right)$ is called $f$-stable if and only if $\lim _{n \rightarrow \infty} \varepsilon_{n}=0$ implies $\lim _{n \rightarrow \infty} x_{n}^{\prime}=w$.

We require the following result to deduce the stability result.

Lemma 1. [4] If $\delta$ is a real number such that $0 \leq \delta<1$, and $\left\{\varepsilon_{n}\right\}_{n=0}^{\infty}$ is a sequence of positive numbers such that $\lim _{n \rightarrow \infty} \varepsilon_{n}=0$, then for any sequence of positive numbers $\left\{u_{n}\right\}$ satisfying

$$
u_{n+1} \leq \delta u_{n}+\varepsilon_{n}, \quad n=0,1,2, \ldots
$$

we have $\lim _{n \rightarrow \infty} u_{n}=0$.

Theorem 5. Let $f: X \longrightarrow X$ be a mapping on a complete b-metric space $(X, d)$ with coefficient $s \geq 1$ satisfying (3). For $x_{0} \in X$, let $\left\{x_{n}\right\}$ be the sequence generated by the iterative scheme $x_{n+1}=\mu\left(f, x_{n}\right), n \geq 0$ as defined in (2). Then the iteration scheme is $f$-stable.

Proof.The existence of the fixed point and the convergence of the iterative sequence defined by (2) is known from Theorem 2. Let $\left\{x_{n}^{\prime}\right\}$ be an arbitrary sequence in $X$ and define $\varepsilon_{n}=d\left(x_{n+1}^{\prime}, \mu\left(f, x_{n}^{\prime}\right)\right), n \geq 0$, where $\mu\left(f, x_{n}^{\prime}\right)=f y_{n}^{\prime}$. Then we have

$$
d\left(x_{n+1}^{\prime}, w\right) \leq s d\left(x_{n+1}^{\prime}, f y_{n}^{\prime}\right)+s d\left(f y_{n}^{\prime}, w\right)=s \varepsilon_{n}+s d\left(f y_{n}^{\prime}, w\right)
$$


Now,

$$
\phi\left(d\left(f y_{n}^{\prime}, w\right)\right) \leq p\left(\phi\left(d\left(y_{n}^{\prime}, w\right)\right)+\phi\left(d\left(y_{n}^{\prime}, f y_{n}^{\prime}\right)\right)+\phi(0)\right) \leq p \phi\left(d\left(y_{n}^{\prime}, w\right)\right)+s p\left(\phi\left(d\left(y_{n}^{\prime}, w\right)\right)+\phi\left(d\left(f y_{n}^{\prime}, w\right)\right)\right)
$$

that is,

$$
\phi\left(d\left(f y_{n}^{\prime}, w\right)\right) \leq k \phi\left(d\left(y_{n}^{\prime}, w\right)\right)
$$

where $k=\frac{p(s+1)}{1-s p}<1$, and therefore

$$
d\left(f y_{n}^{\prime}, w\right) \leq k d\left(y_{n}^{\prime}, w\right)
$$

Hence,

$$
d\left(x_{n+1}^{\prime}, w\right) \leq s \varepsilon_{n}+k d\left(y_{n}^{\prime}, w\right),
$$

where $y_{n}^{\prime}=\mathscr{W}\left(x_{n}^{\prime}, f z_{n}^{\prime}, \alpha_{n}\right)$ and $z_{n}^{\prime}=\mathscr{W}\left(x_{n}^{\prime}, f x_{n}^{\prime}, \beta_{n}\right)$.

Continuing as in the proof of Theorem 2, we get

$$
d\left(x_{n+1}^{\prime}, w\right) \leq s \varepsilon_{n}+k d\left(x_{n}^{\prime}, w\right), \quad n=0,1,2, \ldots
$$

The result then follows from Lemma 1.

In [28], Razani \& Bagherboum defined and proved $(f, g)$-stability result of the Jungck Picard iteration converging to the common fixed point in a $b$-metric space.

Definition 5. [28] Let $(Y, d, \mathscr{W})$ be a convex b-metric space and $X$ be a subset of $Y$, and let $f, g: X \longrightarrow X$ be self mappings such that $f(X) \subseteq g(X)$. For any $x_{0} \in X$, let the sequence $\left\{g x_{n}\right\}$ generated by the iterative scheme (2) converges to $w$. Let $\left\{g x_{n}^{\prime}\right\}$ be an arbitrary sequence, and set $\varepsilon_{n}=d\left(x_{n+1}^{\prime}, \mu\left(f, x_{n}^{\prime}\right)\right), n=0,1,2, \ldots$ Then the iterative scheme $\mu\left(f, x_{n}\right)$ is called $(f, g)$-stable if and only if $\lim _{n \rightarrow \infty} \varepsilon_{n}=0$ implies $\lim _{n \rightarrow \infty} g x_{n}^{\prime}=w$.

Theorem 6. Let $f, g: X \longrightarrow X$ be self maps on a complete b-metric space $(X, d)$ with coefficient $s \geq 1$ satisfying (4). For $x_{0} \in X$, let $\left\{g x_{n}\right\}$ be the sequence generated by the iterative scheme $g x_{n+1}=\mu\left(f, g, x_{n}\right), n \geq 0$ as defined in (2). Then the iteration is $(f, g)$-stable.

Proof. The existence of the unique common fixed point and the convergence of the iterative sequence defined by (2) is known from Theorem 2. Let $\left\{g x_{n}^{\prime}\right\}$ be an arbitrary sequence in $X$ and define $\varepsilon_{n}=d\left(g x_{n+1}^{\prime}, \mu\left(f, g, x_{n}^{\prime}\right)\right), n \geq 0$, where $\mu\left(f, g, x_{n}^{\prime}\right)=f y_{n}^{\prime}$. Then we have

$$
d\left(g x_{n+1}^{\prime}, w\right) \leq s d\left(g x_{n+1}^{\prime}, f y_{n}^{\prime}\right)+s d\left(f y_{n}^{\prime}, w\right)=s \varepsilon_{n}+s d\left(f y_{n}^{\prime}, w\right) .
$$

Now,

$$
\phi\left(d\left(f y_{n}^{\prime}, w\right)\right) \leq p\left(\phi\left(d\left(g y_{n}^{\prime}, w\right)\right)+\phi\left(d\left(g y_{n}^{\prime}, f y_{n}^{\prime}\right)\right)+\phi(0)\right) \leq p \phi\left(d\left(g y_{n}^{\prime}, w\right)\right)+s p\left(\phi\left(d\left(g y_{n}^{\prime}, w\right)\right)+\phi\left(d\left(f y_{n}^{\prime}, w\right)\right)\right)
$$

that is,

$$
\phi\left(d\left(f y_{n}^{\prime}, w\right)\right) \leq k \phi\left(d\left(g y_{n}^{\prime}, w\right)\right),
$$

where $k=\frac{p(s+1)}{1-s p}<1$, and therefore

$$
d\left(f y_{n}^{\prime}, w\right) \leq k d\left(g y_{n}^{\prime}, w\right) .
$$

Hence,

$$
d\left(g x_{n+1}^{\prime}, w\right) \leq s \varepsilon_{n}+k d\left(g y_{n}^{\prime}, w\right),
$$


where $g y_{n}^{\prime}=\mathscr{W}\left(g x_{n}^{\prime}, f z_{n}^{\prime}, \alpha_{n}\right)$ and $z_{n}=\mathscr{W}\left(g x_{n}^{\prime}, f x_{n}^{\prime}, \beta_{n}\right)$.

Continuing as in the proof of Theorem 2, we get

$$
d\left(g x_{n+1}^{\prime}, w\right) \leq s \varepsilon_{n}+k d\left(g x_{n}^{\prime}, w\right), \quad n=0,1,2, \ldots
$$

The result then follows from Lemma 1.

The following is an analogous result for the existence of a unique common fixed point and the convergence of the iteration for a contractive condition similar to (4).

Theorem 7. Let $f, g: X \longrightarrow X$ be commuting self maps on a complete b-metric space $(X, d)$ with coefficient $s \geq 1$ such that there exists $p<\frac{1}{2 s}$ satisfying

$$
\phi(s d(f x, f y)) \leq p(\phi(d(g x, f x))+\phi(d(g y, f y)))
$$

for all $x, y \in X$ with $f(X) \subseteq g(X)$. Then $f$ and $g$ have a unique common fixed point $w \in X$. Moreover, for any $x_{0} \in X$ the sequence $\left\{g x_{n}\right\}$ generated by the Jungck-Picard iteration, $g x_{n+1}=f x_{n}, n \geq 0$ converges strongly to the unique common fixed point.

Proof. The proof is analogous to that of Theorem 3.

Remark. Analogous results for Theorem 4 (and the corresponding corollaries) and Theorem 6 holds true for commuting self maps $f$ and $g$ satisfying (7) with $f(X) \subseteq g(X)$.

\section{Conclusion}

Throughout this paper, we have derived some fixed point theorems for generalized Kannan type mappings in $b$-metric spaces and also introduced a Picard-Ishikawa iteration scheme in a convex $b$-metric space, proving a strong convergence result. Moreover, we defined a generalized Jungck-Kannan type mapping $T$ with respect to $S$ and proved the existence of a unique common fixed point with a convergence result. The rate of convergence of the introduced iteration scheme may be compared to other existing iteration schemes in the literature as a further research.

\section{Competing interest}

The authors declare that they have no competing interest.

\section{Authors' contribution}

All authors have contributed to all parts of the article. All authors read and approved the final manuscript.

\section{References}

[1] A. A. Abdelhakim, A convexity of functions on convex metric spaces of Takahashi and applications, Journal of the Egyptian Mathematical Society 24 (2016), 348 - 354. http://dx.doi.org/10.1016/j.joems.2015.10.003 
[2] S. Agarwal, K. Qureshi and J. Nema, A fixed point theorem for b-metric spaces, Int. J. Pure and Applied Math. Sci. 9, No. 1 (2016), $45-50$.

[3] I. A. Bakhtin, The contraction mapping principle in almost metric spaces, Funct. Anal. 30 (1989), 26 - 37.

[4] V. Berinde, Iterative approximation of fixed points, Springer, 2007.

[5] M. Boriceanu, Fixed point theory for multivalued generalized contraction on a set with two b-metric, "Studia-univ" Babes Bolyai Math. LIV, No. 3 (2009), 1 - 14.

[6] S. Czerwik, Contraction mappings in b-metric spaces, Acta. Math. Inform. Univ. Ostra. 1 (1993), 5 - 11.

[7] D. Das and N. Goswami, A study on fixed points of mappings satisfying a weakly contractive type condition, Journal of Mathematical Research with Applications 36 (2006), 70 - 78.

[8] D. Das and N. Goswami, Some fixed point theorems on the sum and product of operators in tensor product spaces, IJPAM 109 (2016), $651-663$

[9] D. Das, N. Goswami and V. N. Mishra, Some results on fixed point theorems in banach algebras Int. J. Anal. Appl. 13 (2017), 32 -40 .

[10] Deepmala, A Study on Fixed Point Theorems for Nonlinear Contractions and its Applications, Ph.D. Thesis (2014), Pt. Ravishankar Shukla University, Raipur 492 010, Chhatisgarh, India.

[11] H. Faraji and K. Nourouzi, A generalization of Kannan and Chatterjea fixed point theorems in complete b-metric spaces, Sahand Communications in Mathematical Analysis (SCMA) 6, No. 1 (2017), 77 - 86.

[12] J. Górnicki, Fixed point theorems for Kannan type mappings, J. Fixed Point Theory Appl. 19 (2017), 2145 - 2152 , DOI 10.1007/s11784-017-0402-8.

[13] N. Haokip and N. Goswami, Some fixed point theorems for generalized Kannan type mappings in b-metric spaces, Proyecciones (Antofagasta, En línea) 38 (4), 763-782, Oct. 2019.

[14] A. M. Harder and T. L. Hicks, A stable iteration procedure for nonexpansive mappings, Math. Japon. 33, No. 5 (1988), 687 - 692.

[15] S. Ishikawa, Fixed Point by a New Iteration Method, Proc. Amer. Math. Soc. 44, No. 1 (1974), 147 - 150.

[16] G. Jungck, Commuting mappings and fixed points, Amer. Math. Monthly 83 (1976), 261 - 263.

[17] R. Kannan, Some results on fixed points, Bull. Calcutta Math. Soc. 60 (1968), 71 - 76,.

[18] X. Liu, M. Zhou, L. N. Mishra, V. N. Mishra and B. Damjanović, Common fixed point theorem of six self-mappings in Menger spaces using $\left(C L R_{S T}\right)$ property, Open Mathematics 16 (2018), 1423 - 1434.

[19] W. R. Mann, Mean value methods in iteration, Proc. Amer. Math. Soc. 44 (1953), 506 - 510.

[20] L.N. Mishra, On existence and behavior of solutions to some nonlinear integral equations with applications, Ph.D. Thesis (2017), National Institute of Technology, Silchar 788 010, Assam, India.

[21] L. N. Mishra, K. Jyoti and A. Rani, Vandana, Fixed point theorems with digital contractions image processing, Nonlinear Sci. Lett. A 9, No. 2 (2018), $104-115$

[22] L. N. Mishra, S. K. Tiwari and V. N. Mishra, Fixed point theorems for generalized weakly S-contractive mappings in partial metric spaces, Journal of Applied Analysis and Computation 5, No. 4 (2015), 600 - 612. doi:10.11948/2015047

[23] L. N. Mishra, S. K. Tiwari, V. N. Mishra and I. A. Khan, Unique Fixed Point Theorems for Generalized Contractive Mappings in Partial Metric Spaces, Journal of Function Spaces 2015 (2015), Article ID 960827, 8 pages.

[24] S. K. Mohanta, Coincidence points and common fixed points for expansive type mappings in b-metric spaces, Iranian J. Math. Sci. Inf. 11, No. 1 (2016), 101 - 113. DOI: 10.7508/ijmsi.2016.01.009.

[25] M. O. Olatinwo, Some stability and strong convergence results for the, Creative Math. Inf. 17 (2008), 33 - 42.

[26] H. K. Pathak and Deepmala, Common fixed point theorems for PD-operator pairs under Relaxed conditions with applications, Journal of Computational and Applied Mathematics 239 (2013), 103 - 113.

[27] B. Patir, N. Goswami and V. N. Mishra, Some results on fixed point theory for a class of generalized nonexpansive mappings, Fixed Point Theory and Applications 2018, 19 (2018). https://doi.org/10.1186/s13663-018-0644-1

[28] A. Razani and M. Bagherboum, Convergence and stability of Jungck-type iterative procedures in convex b-metric spaces, Fixed Point Theory and Applications 2013, 331 (2013).

[29] J. R. Roshan, V. Parvaneh, S. Sedghi, N. Shobkolaei, W. Shatanawi, Common fixed points of almost generalized $(\psi, \varphi)_{s}$-contractive mappings in ordered b-metric spaces, Fixed Point Theory and Applications 2013, 159 (2013). doi:10.1186/1687-1812-2013-159.

[30] S. L. Singh, C. Bhatnagar and S. N. Mishra, Stability of Jungck-Type Iterative Procedures, International J. Math. \& Math. Sc. 19 (2005), $3035-3043$. 
[31] W. Takahashi, A convexity in metric spaces and nonexpansive mappings, Kodai Math. Sem. Rep. 22, No. 2 (1970), 142 - 149.

[32] B. C. Tripathy, S. Paul and N. R. Das, Banach's and Kannan's fixed point results in fuzzy 2-metric spaces, Proyecciones J. Math. 32, No.4 (2013), 359 - 375. doi: 10.4067/S0716-09172013000400005. 